\title{
UNA INCURABLE PENA MUDA: IMAGEN DE PENÉLOPE EN LA ODISEA DE KAZANTZAKIS
}

\section{Flavio Dalmazzo \\ Universidad Católica Silva Henríquez. Chile}

Resumen: Este artículo explora la imagen de Penélope en la Odisea de Nikos Kazantzakis, prestando especial atención al modo en que su figura contrasta con la de Odiseo, tal y como se deja ver en las primeras dos rapsodias de la obra. Teniendo en miras el juego radical de identidad y diferencia que el escritor cretense ha efectuado sobre el legado de Homero, hemos de observar al fin cómo en esta frágil, borrosa e incluso arruinada Penélope se esconde, a pesar de todo, una cuestión clave del texto kazantzakiano, a saber: la extrañeza, lugar del desencuentro que mueve al héroe moderno a arrojarse nuevamente al viaje, esta vez sin retorno.

Palabras claves: Odisea - Penélope - mudez - Kazantzakis - Homero.

\section{AN INCURABLE MUTE SORROW: IMAGE OF PENELOPE IN KAZANTZAKIS' ODYSSEY}

\begin{abstract}
This article explores the image of Penelope in Nikos Kazantzakis' Odyssey, paying special attention to the way her figure contrasts with Odysseus, as can be seen in the first two rhapsodies of the work. Bearing in mind the radical game of identity and difference that the Cretan writer has made on the legacy of Homer, we will finally observe how in this fragile, blurred and even ruined Penelope it hides, despite everything, a key question of the Kazantzakian text, namely: the strangeness, place of disagreement that moves the modern hero to throw himself on the journey again, this time without return.
\end{abstract}

Keywords: Odyssey - Penelope - muteness - Kazantzakis - Homer.

Recibido: 18.12.2020 - Aceptado: 31.03.2021

Correspondencia: Flavio Dalmazzo

Email: fdalmazzo@ucsh.cl

Profesor adjunto, Instituto de Filosofía P. Juvenal Dho,

Universidad Católica Silva Henríquez, Chile.

ORCID ID: 0000-0003-4762-8084 


\section{¿Pero quién enviaría a un ser tan ligero a juzgar mi vida? Mi pensamiento es profundo y mi memoria es larga; ¿por qué iba yo a envidiar esa libertad cuando tengo humanidad?}

\section{Louise Glück, "La terquedad de Penélope"1}

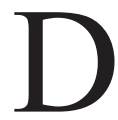
esde que William Bedell Stanford publicara en 1954 su célebre ensayo The Ulysses Theme, que lleva por subtítulo el sugerente nombre de A Study in the Adaptability of a Traditional Hero, hemos podido observar cómo la controversial figura del héroe -acaso la que más de entre la infinidad de personalidades del ciclo épico griego- ha ido acumulando una vasta gama de interpretaciones, lecturas que a su vez proyectan el complejo talante del viajero itacense sobre el paisaje contemporáneo. En efecto, Odiseo parece arribar con ímpetu a las costas del turbulento siglo XX de la mano de autores como James Joyce, Giovanni Pascoli, Derek Walcott y del propio Nikos Kazantzakis, que lo transformaría pronto en una suerte de alter ego. Sin embargo, durante las últimas décadas, como una consecuencia imprevista de tal atención creciente, la abnegada esposa del errabundo Ulises, Penélope, ha ido despertando por igual nuevas miradas, conformándose así en torno a ella un cariz de sentidos e interpretaciones reveladoras que enfatizan críticamente su vigencia. Tendientes a deconstruir la opacidad de un arquetipo mítico signado por la prudencia y la discreción (todo lo que ese recurrente adjetivo homérico $\pi \varepsilon \rho i ́(\rho \rho \omega v$ nombra), estas relecturas vienen en considerable aumento: recreaciones literarias que hallamos, por un lado, en muchísimas tradiciones poéticas ${ }^{2}$, con especial énfasis en las obras de Hilda Doolittle y Louise Glück, o en algunas novelas como La morte di Penelope (2019) de Maria Grazia Ciani, pasando por la más conocida The Penelopiad (2005) de Margaret Atwood, por Toi, Pénélope (2001) de Annie Leclerc y por Penelope (1998) de Silvana La Spina; así como también, por otro lado, aproximaciones teóricas que exploran y redescubren rasgos no atendidos de su figura, como la fortaleza, la independencia, su sagaz política del secreto y arte de la indecisión, su consustancialidad con el tejido como forma de lenguaje cifrado y clave del poema e, inclusive, su carácter de estratega y -cual doblez especular de Odiseo- regente oculta de Itaca. ${ }^{3}$ De modo tal que quizás no sea exagerado pensar que lenta pero

1 Glück 2012, p. 346 (la traducción es mía).

2 A modo de ejemplo, Miguel Castillo Didier (2002) ha traducido tres fascinantes poemas de Yannis Ritsos, Athos Dimulàs y Katerina Angelaki-Rooke sobre la figura de Penélope en el marco de la literatura neogriega; por su parte, Isobel Hurst (2009) revisa su presencia en la poesía norteamericana reciente (en las obras de Linda Pastan, Jorie Graham y Louise Glück, entre otras autoras); mientras que Sandra Gondouin (2010) hace lo propio dentro de la poesía centroamericana, principalmente en algunos textos de Claribel Alegría y Luz Méndez de la Vega. 
sostenidamente va cobrando forma, en el mismo espíritu de Stanford, algo así como el tema de Penélope.

Tal vez por esto mismo, semejante a la manera como se ha ido estudiando la Penélope-Molly Bloom en el Ulises de James Joyce, cabe la pregunta por cómo es que se dibuja Penélope en la monumental e inagotable Odisea de Nikos Kazantzakis, ese "aerolito [que] cayó en 1938 en el lago de las letras helénicas y removió sus aguas", según opinara en su día Dimitrios Nikolareizis (cit. por Castillo Didier 2013, p. 29). Al respecto, y como un horizonte general, convendría partir recordando algunos de los planteamientos que Anguela Kastrinaki señala en un breve artículo reciente, donde repasa, al menos en parte, este asunto.

"No se sorprenderá nadie cuando afirmamos que Kazantzakis no fue particularmente favorable para con la mítica Penélope" (Kastrinaki 2007, p. 194), nos advierte desde un comienzo. Efectivamente, la profesora de la Universidad de Creta explica cómo Kazantzakis elaboró tres imágenes ${ }^{4}$ de Penélope en el curso de su inmensa obra, imágenes distintas aunque marcadas todas por cierta animadversión. Primero, en la novela juvenil Almas rotas (escrita en 1908 bajo el pseudónimo de Petros Psiloritis durante su estancia parisina), donde con una impronta decadentista se deja ver en ciertos pasajes una Penélope cruel, impasible y divinal en medio de un terrible festín, asumiendo un rol de etérea femme fatale. Más tarde, en el breve drama Odiseo (aunque escrito algunos años antes, publicado en 1922 en la revista Nea Zoi de Alejandría), emerge una Penélope turbia, delineada bajo los tonos del cinismo, el eros y la servidumbre, pues cansada de una espera infinita y absurda habría decidido casarse sin más con uno de los pretendientes, Eurímaco, justo un día antes del retorno de Ulises,

Las coacciones del deseo. Antropología del sexo y el género en la antigua Grecia (1990), especialmente su capítulo 5; M. Katz: Penelope's Renown: Meaning and Indeterminacy in the Odyssey (1991); N. Felson-Rubin: Regarding Penelope: from character to poetics (1994); y B. Clayton: A Penelopean Poetics: reweaving the feminine in Homer's Odyssey (2004).

4

A estas tres imágenes cabría añadir una cuarta, que si bien no corresponde propiamente a la figura del mito es un personaje muy secundario en la novela Cristo de nuevo crucificado, con el mismo nombre y con el oficio del tejido como característica. Se trata de la esposa de Ladas, ser tacañísimo y despreciable, cuya ruindad acaso se extienda de soslayo a su mujer Penélope, quien aparece como una viejecilla patética, abstraída y casi muda que no hace más que tejer y tejer calcetas, por completo indiferente a los dramas que azotan a Licovrisí. Así la vemos en distintos pasajes de la novela: "Era una mujer endeble, también ella como su marido en harapos y descalza, con una nariz interminable y colgante que la asemejaba a una vieja cigüeña desplumada [...] ni se dejaba llevar por la cólera, ni se oponía a nada. Era una muerta; caminaba aún, comía, dormía y se despertaba, pero ya no vivía. Poseía el desinterés, la beatitud y la dignidad de los muertos" (Kazantzakis 1954, pp. 68-9); "Penélope clavaba los ojos vacíos plácidamente en las agujas y seguía haciendo calceta. Como si ya viese frente a sí a Caronte y se diese prisa por acabar su labor" (p. 233); "la tía Penélope seguía haciendo calceta sin oír nada [...] trabajando sonriendo, tranquila, inmóvil, muerta” (p. 356). 
supuestamente ordenada en sueños por la diosa Afrodita (cuyo carácter mundanal antagoniza acá con la espiritualidad de Atenea). Por último, como veremos en estas páginas, la encontraremos tenuemente retratada, fantasmal, sumida en el dolor, el resentimiento y el silencio dentro de su obra fundamental, "la tempestad de la Odisea" (Kazantzakis 2012, p. 352), como la llama en una carta a Prevelakis, cuyos primeros esbozos datan de 1924 pero que tras sucesivas reescrituras fue publicada sólo en 1938 .

Así pues, parece un hecho indiscutible que Penélope se presenta de modo muy poco favorable, amargo y hasta cruel a lo largo de la obra del escritor cretense. En efecto, bajo esta luz sombría la vemos perfilarse en la Odisea, en las primeras dos rapsodias, centradas en Itaca. Se tratan estas de rapsodias inaugurales, y por lo mismo preparatorias para el que será el largo derrotero sin retorno del Ulises moderno; pero también rapsodias decisivas, puesto que cumplen la función no menor de enlazar una Odisea con otra: a la vez tributo y herejía respecto al legado de Homero, ejercicio de una delicada e inestable dialéctica de tradición y ruptura. $\mathrm{Y}$ es que la acción comienza en Kazantzakis como directa consecutio ${ }^{5}$ de lo ocurrido en el feroz canto XXII de la Odisea homérica. Allí, recordemos, Ulises se ha deshecho de los andrajos que lo disfrazaban de mendigo y ha resuelto que llegó el momento de revelarse en su verdadera identidad, para cobrar venganza contra los viles pretendientes que devoraban los bienes de la casa y asediaban impunes a su esposa. Es justamente así como lo encontramos ante los ojos estremecidos de la nodriza Euriclea, luego de la matanza:

5 "Kazantzakis comienza atrevidamente su Odisea como una secuela, con la palabra «Y», "Y cuando en su gran patio Odiseo hubo derribado /a los jóvenes insolentes...» (I, 1-2). Persiste en la visión de Kazantzakis mucho del Odiseo homérico”, reflexiona Charles Sean Taylor (1985, p. 42), llamando la atención sobre esa determinante conjunción temporal y consecutiva que da inicio a la rapsodia primera, desatando un inicio in media res del poema kazantzakiano. Tal idea se explica mejor si se tiene en cuenta la traducción

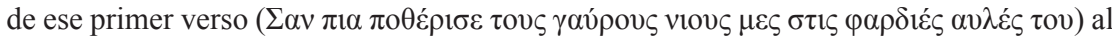
inglés por Kimon Friar: "And when in his wide courtyards Odysseus had cut down /the insolent youths" (Kazantzakis 1958, p. 3); un verso que Miguel Castillo Didier vierte así al castellano: "Cuando a los insolentes jóvenes Ulises hubo muerto /en los vastos patios" (Kazantzakis 2013, p. 55). Es muy llamativo que The Cantos de Ezra Pound, otra obra poética monumental del siglo XX cuyo cometido era igualmente la construcción de una épica contemporánea, comience teniendo en miras a Homero (en concreto, los cantos X y XI de la Odisea), y justamente sea una partícula consecutiva como la de Kazantzakis la que le dé arranque: "And then went down to the ship /Set keel to breakers, forth on the godly sea” (Pound 1994, p. 120). 
descubrió al gran Ulises erguido en mitad de los

todo lleno de polvo y de sangre; un león se diría

muertos,

que retorna, saciado a placer de la carne de un buey

que mató en la manada. Su pecho y sus dos carrilleras

aparecen cubiertas de sangre, terror a los ojos:

tales manchas mostraba él allí de los pies a las manos.

(Homero, Odisea XXII, 401-406).

Sólo algunos instantes más tarde, siglos y siglos mediante, Kazantzakis retoma la acción, en una operación intertextual intensa y formidable. Y es que el cretense no espera hasta el final de la Odisea homérica para dar inicio a la secuela moderna, sino que su escritura irrumpe y se entreteje con audacia a partir del canto XXII (en concreto, hacia el verso 477), detallando entonces los sucesos que serían inmediatamente posteriores. Un deslumbrante viraje de sentido ${ }^{6}$, arraigado en un conocimiento profundo y asimilado del corpus de Homero; una extraordinaria ensambladura. Entre un texto y otro, poco menos de tres mil años: un parpadeo.

De manera que, ya en la Odisea kazantzakiana ${ }^{7}$, partimos contemplando a Ulises en medio de un baño tibio, mientras lava su cuerpo del polvo y la sangre tras la masacre. Es muy significativo que la primera aparición de Penélope no sea de cuerpo entero, sino más bien la de su ausencia visible en la forma de tejidos: huellas mudas de aquel trabajo que volvió tan célebre a su figura. Se trata de unas cuantas "túnicas lucientes", que "habíale bordado /con figuras de inmortales y de navíos y céfiros veloces" (Kazantzakis, Odisea I, 17-18) al aguardado esposo; el mismo que ahora, habiendo regresado a la patria, como un león reposado tras el baño las encontrará colgadas en la pared. Túnicas bordadas, signos materiales del arte de la espera, pero quizás también tejeduras que acusan una disposición más profunda, a saber: que Penélope se ha habituado a la lejanía del esposo, ensoñando sus hazañas y llevando tanto a él como a sus acciones hacia un plano de idealidad. En cualquier caso, el motivo clásico de la tejedora paciente, esposa

6 En palabras de Miguel Castillo Didier: "La obra de Kazantzakis cambia radicalmente el sentido de las tres últimas rapsodias de Homero. El encuentro con Penélope y el reconocimiento, en la rapsodia XXII, pasan a ser episodios distintos; lo mismo sucede con el encuentro y reconocimiento por parte de Laertes, en la rapsodia XXIV. Cambian los rostros del hijo, de la esposa y del pueblo. Empiezan a desaparecer la antigua Itaca y los dioses que guiaban seguros a los hombres preferidos. Ulises siente renacer el fuego de su espíritu. Y sale otra vez a navegar" (2017, p. 43). En tanto, W. B. Stanford complementa: "Kazantzakis no tuvo la obligación de demorarse con devoción en las escenas familiares [...] esta libertad respecto del canon homérico le permitió recrear un Odiseo más homérico [...] al situarse en un ambiente más libre, se acerca más a la figura extravertida de Homero, exhibiendo sus poderes heroicos una vez más en una serie de hazañas y decisiones heroicas, y no en aspiraciones y añoranzas" (2013, p. 270).

$7 \quad$ En adelante, todas las citas a la Odisea de Nikos Kazantzakis corresponderán a la traducción de Miguel Castillo Didier para la edición de Tajamar (2013). 
que aguarda bajo el aura de la fidelidad y la pureza es aquello que se impone primero en la secuela de Kazantzakis. Mito y textualidad recreada, entonces, en el sentido estricto de la Penélope homérica. Y sin embargo, pronto advertimos el viraje radical que el cretense imprimirá sobre la imagen de Penélope, desde que ella hace su efectiva entrada en la escena textual:

Penélope que, silenciosa y pálida, en el trono esperaba, se vuelve a ver y tiemblan sus rodillas de pavor:

«No es éste el que aguardé año tras año, oh, Dios, con grande anhelo,

veo un dragón gigantesco que, semejante a un hombre, nuestra casa pisa»)

(Kazantzakis, Odisea I, 24-27).

Penélope no es aquí la figura protagónica fuerte y memorable de Homero,

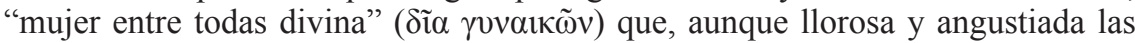
más de las veces, se muestra a ratos plenamente activa, estratega, urdidora tanto con sus manos como en su voũc. Silencio, palidez y pavor son los rasgos que, en cambio, van dando una consistencia melancólica, borrosa y fragilísima a esta otra Penélope de Kazantzakis, quien parece abrumada no ya por la ausencia, sino más bien por la súbita e impetuosa cercanía de aquél a quien esperó por tanto tiempo. "No es éste el que aguardé", se lamenta significativamente. Es que, en efecto, el viaje ha cambiado en lo más hondo al viajero. Odiseo ya no es el mismo ${ }^{8}$. La vastedad de experiencias tras su periplo, la anchura del conocimiento adquirido y las marcas del tiempo lo han transformado en alguien exorbitante, más o menos monstruoso si toca medirse al lado de la cotidiana, apacible y un tanto nimia estatura de la vida en Itaca. "Veo un dragón gigantesco que, semejante a un hombre, nuestra casa pisa", murmura Penélope, en una expresión crucial ${ }^{9}$, cuyo

8 Un efecto de extrañeza que, de acuerdo con la perspectiva de W. B. Stanford, inserta al Ulises de Kazantzakis en una tradición que, a contramano del impulso centrípeto original, recepciona y recrea al héroe en su carácter centrifugo, i. e., hacia afuera, rebelde, experimentador, anárquico, inconforme, en dirección a lo exótico: "En el intento de definir la esencia de este Ulises neogriego [...] Kazantzakis ha tomado de la épica temprana muchas de la cualidades y aventuras de su héroe. Pero en esencia, su Ulises es un avatar del héroe centrífugo de Dante, y proviene de la tradición que conduce desde Dante, pasando por Tennyson y Pascoli, hasta el presente" (Stanford 2013, p. 281).

9 La figura adjetival del dragón es recurrente en el poema: "No es este un rey, no es un pastor de pueblo; /sólo un dragón hambriento que ha olisqueado en torno carne humana" (Kaz. Od. I, 989-990), le oímos maldecir, por ejemplo, a un anciano en otro momento. Se trata en general de una figura que da cuenta de cierta ferocidad, vitalidad exuberante, por encima del bien y el mal, sobrehumana por demasiado humana. Aunque confluyen en ella ecos de leyendas populares vinculadas a las hazañas de San Jorge, es más una caracterización de lo animal-bestial en la cual resuena la idea de lo demoníaco de Stefan Zweig y, por sobre todo, el pensamiento de Nietzsche, ese "alimento de león" 
fin pareciera no ser otro que confesar, con cuotas enormes de terror y angustia, el giro inquietante, infamiliar, el desborde de toda escala humana y la amenaza efectiva que representa ahora Odiseo ante sus ojos. Su crueldad la apabulla, la mueve a recogerse en el silencio y en la desaparición. Es así como a instancias del banquete de bienvenida donde Itaca celebra al rey retornado, pese a estar invitado el pueblo entero, otra vez Penélope brilla por su ausencia: su trono "vacío veíase y desierto, porque se avergonzó de súbito Penélope /de aparecer ante el pueblo después de tantas muertes" (Kazantzakis, Odisea I, 1025-1026). Mas no se trata, cabe argüir, sólo de pudor, prudencia o timidez. Antes bien, de un temor fundado en la sensación de que Ulises representa un auténtico peligro que ella quisiera, no sin ambages y contradicciones, tener lejos, muy lejos nuevamente. ${ }^{10}$

A medida que la extrañeza de Odiseo respecto a su patria se acrecienta -"vine a anclar aquí para podrirme en la patria" (Kazantzakis, Odisea I, 1222), "ahora comprendía, también era la patria rostro dulce de muerte" (Kazantzakis, Odisea II, 435), ${ }^{11}$ "mi patria es el exilio" (Kazantzakis, Odisea II, 1133), leemos-,

tan importante en la conformación del imaginario de Kazantzakis. Así, en el horizonte de un nietzscheano "amor irrefrenable por la vida y una recuperación de las fuerzas vitales en el hombre", explica Roberto Quiroz, "La animalidad viene a ser un símbolo del sentido de la tierra, una manera de apegarse al mundo concreto, al mundo de los sentidos [...] Kazantzakis valoró al máximo toda esa aceptación de la vida” (2010, pp. 252-253). Y en otra oportunidad: "Ulises, el hombre de las mil aventuras, parece llegar a ser la corporeización, «la materialización del superhombre, una realización monumental, encantadora, invencible»" (Quiroz 2003, p. 107). A tal punto la fiera vitalidad de Ulises desborda todos los marcos que al parecer se tradujo en un dilema formal que Kazantzakis experimentó durante la escritura de la Odisea, según relata años después en su autobiografía, donde dialogando con su personaje le imputa: "Pero tú haces estallar la palabra - ¿cómo podría contenerte?” (Kazantzakis 1963, p. 394).

10 Hay, en efecto, un instante al comienzo de la rapsodia primera que destaca por su atrocidad, y es cuando Odiseo, mientras rememora los estertores de la guerra, torva y alienada su mirada apunta a Penélope, a quien parece querer desgarrar: "¡la hubiera atravesado con su espada en el ardor de la pelea!” (Kaz. Od. I, 38), piensa para sí. Misma sensación rencorosa ocurre luego respecto a Itaca: "En su agitado pecho brotó como un relámpago el anhelo /de caer sobre la isla y pasar a cuchillo /a dioses y hombres y mujeres, y en la vasta playa calcinada /desparramar al alba las cenizas de la patria" (Kaz. Od. I, 83-6).

11 Esta idea de la patria como máscara de la muerte, obstáculo que retiene y que debe, por lo mismo, ser enfrentado y dejado atrás, se corresponde con un motivo persistente, transversal en el pensamiento de Kazantzakis: la quema de etapas en miras a la liberación, como una forma de lucha sin fin. Se trata de una dimensión que Manuel Naranjo comprende como desprendimientos místicos, ascensión en busca de la llama interna del hombre (cit. en Castillo Didier 2007, pp. 44-5), y que el propio Kazantzakis vincula en Carta al Greco con el develamiento de Odiseo como la vertical de su obra: "El gran Compañero de Ruta sabe cuál es su adversario, pero el pánico no lo domina; eleva la mirada y contempla cómo cambia el rostro de la muerte y adquiere innumerables 
también su mirada sobre los distintos miembros de la familia se torna más hosca, despiadada. El padre Laertes le parece sumido en decadencia -"su mente se hizo limo" (Kazantzakis, Odisea I, 999) -, el hijo Telémaco preso de una prudencia medrosa, inexperta y hasta senil -"como un anciano octogenario, todo lo pesa con cuidado" (Kazantzakis, Odisea II, 440) -, y he aquí la brutal descripción de Penélope: es una miserable mujercilla que solloza, una "dueña de casa ya marchita" (Kazantzakis, Odisea II, 439). Todas las palabras elegidas y las cualidades resaltadas por Kazantzakis en estas dos primeras rapsodias contribuyen pues a subrayar la pobreza de Itaca, y en consecuencia a justificar el deseo del héroe de volver a partir: "una sensación de desencanto empieza a hacerse fuerte en él. El hogar y la isla tan anhelados se le hacen estrechos y enseguida asfixiantes", apunta Roberto Quiroz (2003, pp. 319-320), graficando bien esa mezcla de sofocación y hostilidad que altera las imágenes de su entorno. Y mientras más ve Odiseo cristalizar dentro de sí la idea de una segunda partida, que Kazantzakis caracteriza con distintos ecos y figuras de la fuerza marina -"y brincaban peces y bajeles, en cardúmenes, dentro de su espíritu" (Kazantzakis, Odisea II, 731) -, Penélope tiende a desdibujarse, opacarse trágicamente de cara a lo que comienza a intuir como inevitable.

En la segunda rapsodia, cuyo eje temático central son los preparativos para la huida de Itaca, Penélope comparece aún más retraída por el presentimiento del nuevo abandono, que ella columbra como definitivo. Así, la noche siguiente a los festejos populares de bienvenida, mientras Odiseo se apresta ante el fogón

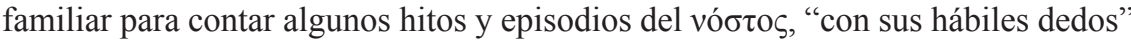
se dispone ella a tejer un peplo sobre "los padecimientos y penas de su esposo" al tiempo que vuelve a mostrarse como una presencia sombría, ensimismada: "con los ojos llorosos, / se dobla como el lino fino, como la espiga tiembla: / ya llegaron las olas y golpean su pecho oprimido" (Kazantzakis, Odisea II, 6-8). El paralelismo de esta imagen poética elaborada por Kazantzakis es elocuente: Penélope es una tela de lino delicadísima y es una espiga frágil que tiembla; por otro lado, están las olas furiosas, la inmensidad machacadora del mar, cuya materia parece impactar en el espíritu de Penélope como un revoltijo de amenazas, daño, incertidumbre, dolores venideros. Forma del poderío frente a la impotencia, el mar es un tremendo arrebatador -recordemos un epíteto kazantzakiano: la mar como "la-que-separa-esposos" (Kazantzakis, Odisea II, 849 ) - que, ella lo sabe, la volverá a dejar en un estado de desolación irresoluble. Acaso el cenit del patetismo trágico de esta Penélope de Kazantzakis pueda resumirse en estos versos:

máscaras -ya una mujer en la arena que canta con las manos en la garganta, ya un dios que levanta tempestades y quiere devorarla, ya un humo ligero encima del techo de su casa [...] muy al principio, cuando aún no te conocía, coloqué en tu camino, para impedirte partir, lo que yo creía la trampa más hábil, a Itaca. Pero tú habías reído a carcajadas, respirado profundamente e Itaca había sido pulverizada. Fue entonces cuando comprendí, alabado seas tú, destructor de patrias, que Itaca no existe: no hay más que el mar y una barca minúscula" (1963, pp. 393-4). 
Disponía su pobre mujer que canten las esclavascon sus voces dulces para que apaguen el rumor del mar.

Pero él estaba siempre entre las velas y contemplaba el ponto:

brisas, olas, aves, voces, eran sus mesas preparadas

(Kazantzakis, Odisea II, 732-5).

Con la ayuda de sus siervas, tal vez un modo sutil de solidaridad femenina, Penélope intenta distraer al febril esposo, apartar de su mente el mar, retardar la partida que trama junto a sus amigos. Por supuesto, sin éxito. Mientras Odiseo permanece en Itaca, ella, "mujer discreta, siente en silencio estrecharse el lazo / alrededor del cuello de su esposo" (Kazantzakis, Odisea II, 1112-3), a la par que queman "su fiel corazón" todos los rumores que empiezan a correr en torno a él y sus vagos amigos -tildados de leones u, otra vez, dragones- que festejan bestiales, báquicos en la playa donde construyen la nave para zarpar. Un escenario funesto para Penélope que, en su soledad, ira y humillación, se dice a sí misma arrancándose rabiosa los cabellos:

«¡Ojalá que en otras costas aún errara y ver el humo deseara levantarse del tejado del hogar, pero nunca, dios mío, lograran tocar sus manos la tierra de la patria!»

(Kazantzakis, Odisea II, 1117-19).

Deseos vengativos que no son otra cosa que una réplica frente a la hostilidad recibida. Penélope anhela que Odiseo se vaya, o más bien quisiera que nunca hubiese llegado. Le desea, cual presagio, una errancia sin fin. "Algo más todavía: desea su muerte", piensa Anguela Kastrinaki (2007, p. 200). Y es que la espera también ha cambiado a Penélope. Ella tampoco es la misma. ${ }^{12}$ Como contestación adopta entonces una actitud estratégica, sólo en apariencia pasiva: la mudez. Una mudez que es fruto de cierta dignidad y orgullo, al no dejar que su dolor se revele. Mudez amarga, pero también política de "la pobre mujer de-mano-de-oro" que muerde sus labios "para que el sollozo se ahogara dentro de su amargo cuello níveo" (Kazantzakis, Odisea II, 197). Reacción airada, amalgama de frustración, rencor y extrañeza ante quien ya no se parece en nada -porque desborda- al que veinte años antes hubo partido. Y aunque ya todo alrededor suponga estrechez y decepción para Odiseo, no deja de ser revelador un momento de la rapsodia cuando, en plenas bodas de Telémaco, ve él descender de la nave a la que se

12 Es muy interesante contrastar este devenir identitario del Ulises y la Penélope kazantzakianos a la luz de lo que observa Erich Auerbach: "Los héroes homéricos están tan poco representados en su devenir y en lo que han devenido, que [...] aparecen con una edad estancada desde el principio. Incluso Ulises, que ofrece ocasión señalada para un desarrollo histórico, a causa del largo tiempo de su periplo y de los muchos sucesos que en él tienen lugar, apenas si da muestras de algo semejante [...] Penélope apenas si ha cambiado en veinte años [...] en definitiva, Ulises es completamente el mismo al regreso que cuando, dos décadas antes, abandonó Itaca” (1996, p. 23). 
convertirá en la esposa de su hijo, Nausícaa, y su mente entonces viaja de súbito al pasado para recordar el temblor de juventud al tocar, aún vacilante, a su mujer por primera vez. Casi un desliz del poema, donde la voz narradora describe en su ánimo un destello de empatía y comprensión: "sintió la tristeza inconfesable /de la mujer" (Kazantzakis, Odisea II, 1199-1200).

La aparición final de Penélope en la nueva Odisea no viene sino a remarcar el talante infeliz de su figura. Se da cuando Ulises llega a pasar la última noche en el lecho matrimonial antes de escabullirse silencioso al alba, para no volver jamás. No hay palabras, miradas o gestos de despedida; ni siquiera roce físico. Son dos extraños compartiendo la cama: una frágil y humana Penélope, un impetuoso y sobrehumano Odiseo. ${ }^{13}$ Se trata de una escena marcada por la frialdad y la dureza de quien se marcha "sin volverse hacia atrás" (Kazantzakis, Odisea II, 1461). Pero ocurre que Penélope en su triste lucidez, en su adusta inteligencia, no dormía realmente; con párpados cerrados, en vela, prevé, sabe ya de la partida: "y sellaba sus labios una incurable pena muda" (Kazantzakis, Odisea II, 1457), leemos, justo antes de verla desgarrándose piel y cabellos, para por fin desaparecer del texto.

Ahora bien, llegados a este punto conviene retornar a una pregunta que la profesora Kastrinaki se hace respecto al tratamiento que recibe Penélope en la Odisea de Kazantzakis: “¿Acaso es malo con ella solamente Odiseo, mientras que el autor reconoce sus derechos y sufre con ella"? (Kastrinaki 2007, p. 199). Se trata de una pregunta punzante, que convoca al problema de la intencionalidad, la estructura poética y el sentido. Una pregunta de difícil solución, que ella, sin embargo, responde taxativa: "No, entonces. No es sólo Odiseo que rechaza a Penélope; es también el autor" (p. 200). Sea como fuere, lo que sí nos parece posible deslizar aquí, a modo de cierre, son dos conclusiones tentativas.

En primer lugar, podríamos afirmar que la caracterización de Penélope en las rapsodias iniciales del texto kazantzakiano está determinada por el signo de la fragilidad, el silencio y el temor. Sus rasgos son pobremente delineados, al punto que es algo menos que un personaje secundario ${ }^{14}$ apenas un par de veces, de hecho, es llamada por su nombre, como recuerda Miguel Castillo Didier (2002, p. 227). Pero esta debilidad en su trazado poético es, no obstante, coherente en términos formales con la visión que Odiseo tiene de Itaca tras su retorno: decepción, penuria, estrechez. Así, el retrato de Penélope no podía ser

13 Establece aguda y críticamente Anguela Kastrinaki los términos de esta oposición subterránea en el texto: "él es el sol, el fuego, el dragón, y ella la muda, la pálida (sin luz) y la aterrorizada. Joven él [...] vieja Penélope [...] Con una actividad febril Odiseo; totalmente pasiva Penélope" (2007, p. 198).

14 Al respecto, conviene no perder de vista lo que Helena González-Vaquerizo analiza y señala sobre el rol de las mujeres dentro de la obra del cretense: "En la obra de Kazantzakis, las mujeres aparecen ya sea como un «ayudante» o como el antagonista del personaje masculino, el héroe [...] Sin embargo, creo que hay mujeres fuertes en la obra de Kazantzakis, mujeres que a menudo amenazan a sus homólogos masculinos incompletos, pero que también pueden ser el medio para lograr la síntesis y la integridad de la pareja" (2018, p. 345). 
quizás otro. Pues refuerza estructuralmente, en su palidez y falta de vitalidad, la pulsión centrífuga y excesiva del héroe, que lo lleva a despreciar la tierra patria y la familia para volver a echarse al mar; siendo a su vez él mismo despreciado por el temperamento doméstico, arraigado, centrípeto de su esposa, quien ha elegido callar y desaparecer. En este sentido, la fragilidad de Penélope está en relación estricta - por contraposición- con la rotundidad salvaje de Odiseo.

Con todo, y en segundo lugar, es importante notar cómo Penélope resulta imprescindible en la construcción de la poética de la Odisea de Kazantzakis. Y es que su imagen, aunque feble, contribuye decisivamente a explicitar el giro que el escritor cretense ha realizado sobre el legado de la tradición homérica, por cuanto de su desencuentro con Odiseo surge el sentido singularísimo de esta epopeya neogriega. Pues si es verdad que en Homero "el objetivo del viaje de Ulises es recuperar a Penélope, la mujer fiel, la que durante cuatro años engañó a los pretendientes tejiendo un velo durante el día y destejiéndolo durante la noche", siendo esto lo que "le da sentido a todo el poema", como afirma Pierre VidalNaquet (2011, pp. 29 y 70); y si es verdad también que sólo "en el espejo de los ojos de Penélope [...] Ulises reconquista plenamente su identidad heroica y recupera el lugar que le corresponde, como esposo, padre y rey", según explican Françoise Frontisi-Ducroux y Jean-Pierre Vernant (1999, p. 40), se comprende en su raigambre más profunda la audaz innovación poética de Kazantzakis como re-creador del mito, como continuador-y-disidente de Homero. Y es que en los ojos opacos y apagados - por el dolor; mas también por voluntad, como forma de réplica y antifaz- de Penélope, el Odiseo moderno no habrá de reflejarse, no habrá de encontrarse, sin poder recuperar nunca más ese lugar que le era radicalmente propio. Doble extrañeza entonces, asunto de no-correspondencia y, en definitiva, desencuentro fundamental que acaso sea el germen del nuevo peregrinaje sin retorno de un Ulises que tiene poca o, quizás, demasiada, rebosante humanidad. Al punto de extraviarla. Tal vez por ello resuenan con visionario y estremecedor sentido esos reproches que Penélope arroja a su esposo en la carta de las Heroidas, donde no por nada lo llama "hombre sin corazón" (Ov. Her. I, 58).

\section{REFERENCIAS BIBLIOGRÁFICAS}

AUERBACH, E. (1996) Mimesis. La representación de la realidad en la literatura occidental. México D. F.: Fondo de Cultura Económica.

CASTILLO DIDIER, M. (2017). El tiempo, la muerte y la palabra en la Odisea de Kazantzakis. Santiago: Centro de Estudios Griegos, Bizantinos y Neohelénicos "Fotios Malleros".

--- (2013). "Dos Odiseas", en N. KaZAnTZaKis: Odisea. Santiago: Tajamar, pp. 7-51.

--- (2007). La Odisea en la Odisea. Estudios y ensayos sobre la Odisea de Kazantzakis. Santiago: Centro de Estudios Griegos, Bizantinos y Neohelénicos "Fotios Malleros".

--- (2002). "Homero en Kazantzakis: el llanto de Penélope", Byzantion Nea Hellás, 21, pp. 219-238. 
FRONTISI-DUCROUX, F. Y VERNANT, J. (1999). En el ojo del espejo. Buenos Aires: Fondo de Cultura Económica.

GLÜCK, L. (2012). Poems 1962-2012. New York: Farrar, Straus and Giroux.

GONDOUIN, S. (2010). "Penélope y Ulises en la poesía contemporánea de América Central", Centroamericana, 18, pp. 31-50.

GONZÁLEZ-VAQUERIZO, H. (2018). "Caracteres de mujeres paralelas y feminidad en la obra de Durrell y de Kazantzakis", Byzantion Nea Hellás, 37, pp. 341-356.

HOMERO. (2000). Odisea. Trad. de José Manuel Pabón. Madrid: Gredos.

HURST, I. (2009). “'We'll all be Penelopes then': Art and Domesticity in American Women's Poetry, 1958-1996", en S. HARRISON (ed.): Living Classics: Greece and Rome in Contemporary Poetry in English. Oxford: Oxford University Press, pp. 275-294.

KASTRINAKI, A. (2007). "Kazantzakis y las Penélopes", Byzantion Nea Hellás, 26, pp. 193-202.

KAZANTZAKIS, N. (2013). Odisea. Traducción y estudios de Miguel Castillo Didier. Santiago: Tajamar.

--- (2012). The selected letters of Nikos Kazantzakis. Ed. y trad. de Peter Bien. New Jersey: Princeton University Press.

--- (1963). Carta al Greco. Itinerario espiritual autobiográfico. Buenos Aires: Ediciones Carlos Lohlé.

--- (1958). The Odyssey. A Modern Sequel. Translation, introduction, synopsis and notes by Kimon Friar. London: Secker and Warburg.

--- (1954). Cristo de nuevo crucificado. Buenos Aires: Ediciones Carlos Lohlé.

OVIDIO. (2010). Heroides (o cartas de las heroinas). Trad. de Antonio Ramírez. Madrid: Akal.

POUND, E. (1994). Cantares completos. Madrid: Cátedra.

QUIROZ, R. (2010). "Kazantzakis-Nietzsche, un discipulado vital", Byzantion Nea Hellás, 29, pp. 231-263.

--- (2003). Nikos Kazantzakis. Dimensiones de un poeta-pensador. Santiago: Centro de Estudios Griegos, Bizantinos y Neohelénicos "Fotios Malleros".

STANFORD, W. (2013). El tema de Ulises. Traducción Alfonso Silván y B. Afton Beattie. Madrid: Editorial Dykinson.

TAYLOR, C. (1985). "La fidelidad a la tierra en el Odiseo de Nikos Kazantzakis", Byzantion Nea Hellás, 7-8, pp. 35-54.

VIDAL-NAQUET, P. (2011). El mundo de Homero. Buenos Aires: Fondo de Cultura Económica. 